\title{
PATRONES DE LA VEGETACIÓN Y TIPOS DE USO DE LA TIERRA EN EL VALLE DEL PATÍA
}

\section{Vegetation patterns and land use types in the Patia valley}

\author{
Hernando Vergara Varela ${ }^{1}$
}

Vergara V, H. (2015). Patrones de la vegetación y tipos de uso de la tierra en el valle del Patía. Colombia Forestal, $18(1), 25-45$

Recepción: 20 de julio de 2014

Aprobación: 5 de diciembre de 2014

\section{RESUMEN}

La vegetación del ecosistema de bosque seco del Valle del río Patía en el departamento del Cauca ha sido alterada y sustituida por cultivos y pastizales. Los remanentes boscosos se caracterizaron en función de su estructura y composición florística en altitudes comprendidas entre 500 y 800 m de altitud. Se evaluaron los cambios de cobertura usando fotografías aéreas y una imagen satélite y se relacionaron con los tipos de uso. Los datos fueron analizados a través de procedimientos multivariados usando el programa TWINSPAN con el fin de producir una clasificación de la vegetación, determinando seis tipos estructurales y seis tipos florísticos. El gradiente florístico arrojado por el programa describe tipos estructurales que van desde bosques y arbustales hasta herbazales. Las comunidades vegetales reflejan estados sucesionales de los fragmentos, la comunidad de Citharexylum kunthianum contrasta con los bosques riparios determinados por la comunidad de $E u$ genia sp., especie dominante y abundante en áreas intervenidas. La comunidad de Handroanthus chrysanthus muestra una transición hacia la vegetación de matorrales xerofíticos del sur del país. Los tipos de uso de la tierra y las clases de cobertura han permanecido desde 1961, se destaca el incremento de la cobertura de pastizal. Los estratos identificados muestran que los bosques secos tropicales se encuentran reducidos en su estructura, atendiendo a que son bosques perturbados.

En la larga historia de uso y de perturbaciones que lleva esta área, se evidencia una reducción de los fragmentos de bosque; los factores sociales y económicos son una fuerza de cambio de las comunidades vegetales en áreas rurales.

Palabras clave: bosque seco tropical, cambios de cobertura, cobertura vegetal, Colombia, comunidades vegetales, Patía, uso de la tierra.

\begin{abstract}
Vegetation of dry forest ecosystem of the Patia Valley located in the department of Cauca has been altered and replaced by crops and pastures. The forest remnants were characterized in terms of their structure and floristic composition at altitudes between 500 and $800 \mathrm{~m}$. This study evaluated changes in land cover using aerial photographs and satellite image as input to produce land cover maps in order to assess changes associated with land use types. Data were analyzed by multivariate methods using the TWINSPAN program to produce a vegetation classification, identifying six vegetation structure types and
\end{abstract}

1 Universidad del Cauca. Popayán, Colombia. hernandov@unicauca.edu.co

http://dx.doi.org/10.14483/udistrital.jour.colomb.for.2015.1.a02 
six floristic types. The floristic gradient thrown by the program describes structural types, ranging from forests to shrublands and grasslands. Successional plant communities reflect conditions of the fragments, Citharexylum kunthianum community contrasts with riparian forests determined by Eugenia $\mathrm{sp}$ the dominant specie in disturbed areas. Handroanthus chrysanthus community shows a transition to xerophyte vegetation of the south of Colombia. Land use types and land cover classes have remained since 1961, increasing pasture cover. Tropical dry forests are reduced in its structure, considering that forests are disturbed.

In the long history of the land use and disturbance of this area, a reduction in forest fragments is evident, social and economic factors are a force for a change in plant communities in rural areas.

Key words: dry tropical forest, cover change, vegetation cover, Colombia, plant communities, Patía, land use.

\section{INTRODUCCIÓN}

El Valle del Patía presenta pocos remanentes boscosos debido a las actividades humanas; la ganadería y la agricultura siguen siendo las principales actividades de la región mientras que las actividades extractivas han desaparecido. La degradación del suelo, como resultado de extremos en la variación climática, de las prácticas no sostenibles en el uso de la tierra, incluyendo tala excesiva de los bosques, han llevado a procesos de desertificación (Díaz, 2006). Las áreas secas del departamento del Cauca según el Ministerio del Medio Ambiente (2002) están consideradas entre las áreas potenciales a la desertificación, debido principalmente a la pérdida de sus coberturas boscosas.

La vegetación del valle del Patía hace parte del bosque seco tropical (bs-T), como una formación vegetal definida por características de precipitación, biotemperatura y evapotranspiración, tomando por modelo de clasificación de formaciones vegetales propuesto por Holdridge (1996); el bosque seco tropical es una formación que se presenta con temperaturas entre 17 y $25 \mathrm{C}^{0}$, precipitaciones entre $700 \mathrm{~mm}$ y $2000 \mathrm{~mm}$ con uno o dos periodos marcados de sequía. Los bosques secos tropicales se caracterizan por presentar precipitaciones menores a $100 \mathrm{~mm}$ durante cinco a seis meses y una vegetación decidua durante el periodo más seco (Pennington, 2000).
La población humana ha modificado las comunidades vegetales y en aquellos lugares donde la vegetación natural y seminatural permanece, los límites de las comunidades vegetales se encuentran bien definidos (Kent \& Coker, 1992). Además, frecuentemente en diferentes tipos de uso, existen pequeñas áreas donde la vegetación natural aún crece. El uso de la tierra en el valle del Patía es referido a las actividades agrícolas, ganaderas y extractivas. Debido a las actividades de uso, grandes extensiones de bosque seco tropical han desaparecido, las relaciones entre cobertura y uso de la tierra explican la reducción de las áreas de bosque.

Los objetivos son: caracterizar los patrones de la vegetación y los tipos de uso de la tierra en el Valle del Patía y determinar los cambios de cobertura a través de un análisis histórico de fotografías aéreas del lugar de estudio. El análisis enfatiza en las características de la estructura y composición florística de la vegetación y los tipos de uso, presentando el mapa de uso y cobertura para el año 2011 y los cambios de cobertura desde el año 1961 a 2011.

\section{MATERIALES Y MÉTODOS}

\section{Área de estudio}

El valle del río Patía está localizado entre los $1^{\circ}$ $15^{\prime} \mathrm{N}, 77^{\circ} \mathrm{W}$ y $2^{\circ} 15^{\prime} \mathrm{N}, 77^{\circ} 20^{\prime} \mathrm{W}$, en el sur-occidente colombiano, departamento del Cauca. 
Son áreas más o menos planas, de moderada altitud y cubiertas por pasturas de origen antrópico o rastrojos. La vegetación original ha sido destruida para ser sustituida por cultivos y pastizales para ganadería. Las quemas fueron un elemento importante en la transformación de dichos ecosistemas, por lo tanto la posibilidad de encontrar vegetación nativa es baja. Quedan algunos relictos de bosque situados cerca de las riberas de las quebradas o pequeñas extensiones en las áreas planas o en relieves colinados.

Las áreas secas objeto de estudio se encuentran entre los 500 y 800 m de altitud, la temperatura media anual es de $26.3^{\circ} \mathrm{C}$ y la precipitación media anual es de 1248 mm. (Estación climatológica Granja Experimental Universidad de Nariño, municipio de Mercaderes, departamento del Cauca $\left(01^{\circ} 54^{\prime} \mathrm{N}, 77^{\circ} 11^{\prime} \mathrm{W} ; 580 \mathrm{~m}\right.$ altitud). La precipitación media anual en la Estación Patía es de 1600 $\mathrm{mm}$, municipio de Patía, departamento del Cauca $\left(02^{\circ} 4^{\prime} \mathrm{N}, 77^{\circ} 03^{\prime} \mathrm{W} ; 680 \mathrm{~m}\right.$ de altitud).
La precipitación tiene una distribución bimodal, dividida en dos periodos lluviosos (marzomayo y octubre-diciembre) que son separados uno del otro por dos periodos secos (enero-febrero y junio-septiembre). Las características secas del valle del Patía están dadas por la escasez de las Iluvias durante los meses de junio-septiembre que se relacionan con las altas temperaturas y alta evaporación (1600 mm).

Se identificaron en la zona tres grandes áreas que se abordaron y analizaron desde la perspectiva de la distribución de la vegetación en espacio / tiempo, así como también la posibilidad de detectar cambios en las características de la cobertura y del uso de la tierra en el tiempo.

Las áreas (Figura 1) fueron seleccionadas teniendo en cuenta criterios de uso de la tierra y características de la vegetación, así: Área 1 (Versalles, $2^{\circ} 4^{\prime} 24^{\prime \prime} \mathrm{N}, 77^{\circ} 5^{\prime} 26^{\prime \prime} \mathrm{W}$ ) presenta tierras dedicadas a la ganadería principalmente y pequeñas parcelas para uso agrícola; la vegetación consiste

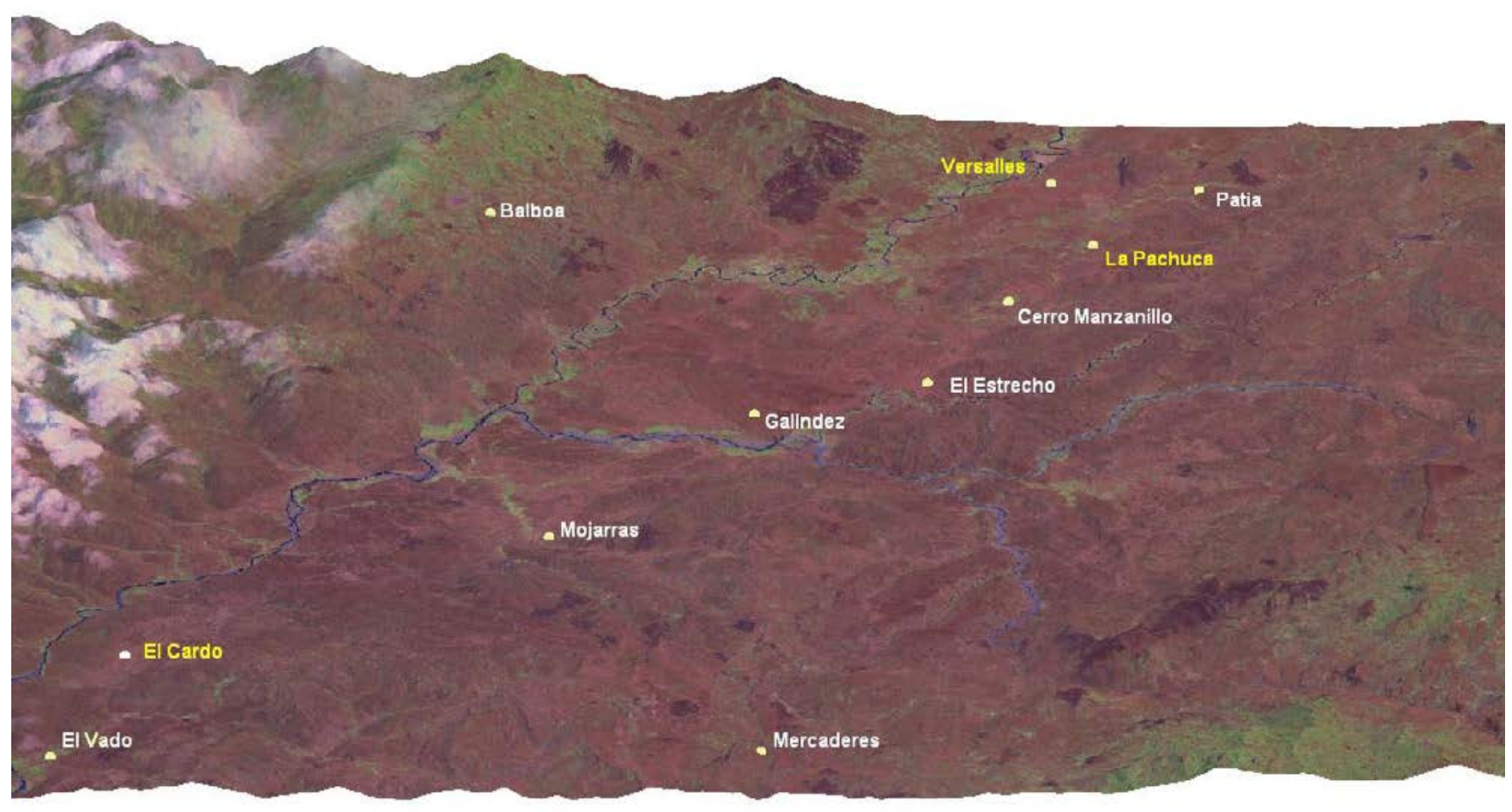

Figura 1. Ubicación de las áreas de estudio: a) Versalles b) La Pachuca c) El Cardo. 
de árboles esparcidos en los potreros y pequeños relictos a las orillas de quebradas y ríos en terrenos planos y de colinas bajas. Área 2 (La Pachuca, $2^{\circ} 2^{\prime} 31^{\prime \prime} \mathrm{N}, 77^{\circ} 4^{\prime} 27^{\prime \prime} \mathrm{W}$ ) presenta tierras dedicadas principalmente a la agricultura y la ganadería, se reconocen relictos de bosque que no han sido intervenidos recientemente en áreas planas y piedemontes de colinas. Área 3 (El Cardo, $1^{\circ} 51^{\prime} 05^{\prime \prime}$ $\left.\mathrm{N}, 77^{\circ} 15^{\prime} 42^{\prime \prime} \mathrm{W}\right)$ presenta parches de arbustales y matorrales xerofíticos, son áreas de montaña y se localizan pequeñas parcelas de subsistencia en áreas de colinas.

\section{Caracterización de los patrones de la vegetación y los tipos de uso de la tierra}

\section{Caracterización de la vegetación}

Se realizaron 67 levantamientos en parcelas de 10*10 m con el fin de caracterizar la vegetación en cada remanente de bosque, acorde con lo propuesto por Gentry (1988) con algunas modificaciones, teniendo en cuenta que el valle del Patía ha sido sometido a un proceso de deforestación continuo y muchos de los relictos boscosos son parches dispersos y de áreas pequeñas $(<1$ ha).

La vegetación se describió en términos fisonómicos y florísticos. Para la descripción fisonómica se tuvieron en cuenta las categorías estructurales como son la estratificación y la cobertura. La estructura vertical de la vegetación del Patía se describió atendiendo al porcentaje de cobertura del estrato, según lo propuesto por Rangel \& Lozano (1986) para gradientes montañosos y lo descrito por Murphy \& Lugo (1986) para bosques secos. La descripción florística incluyó la identificación de las especies, teniendo en cuenta la disposición de los individuos en los diferentes estratos. El porcentaje de cobertura de cada estrato y porcentaje de la cobertura de la especie por estrato se hizo de acuerdo a la escala de Braun-Blanquet (Van der Hammen et al., 1989); incorporando datos de altura, especies dominantes en cada estrato y la cobertura total. La identificación de las muestras vegetales se hizo en el herbario CAUP de la Universidad del Cauca y en el herbario CUVC de la Universidad del Valle, herbarios donde se depositaron las muestras; la colecta se realizó siguiendo los estándares de herborización.

\section{Análisis de la vegetación}

La estructura de la vegetación se clasificó a través de un análisis de conglomerados usando el programa TWINSPAN (Hill \& Smilauer, 2005), basados en los parámetros de porcentaje de cobertura y altura de cada estrato. La estructura de la vegetación también fue clasificada atendiendo al modelo de Wyngaarden (1985) a través de una gráfica en dos dimensiones fundamentada en el porcentaje de cobertura total por estrato en cada parcela, tomando como referencia únicamente la cobertura arbustiva y arbórea teniendo en cuenta que el objeto es conocer el estado de los bosques.

La composición florística de la vegetación fue analizada atendiendo a sus preferencias ecológicas, con este objeto se utilizó el programa TWINSPAN de clasificación numérica a fin de realizar un análisis de conglomerados basado en el concepto de agrupamiento, en donde cada grupo representa especies con características similares en un espacio matemático (Kent \& Coker, 1992). El programa construye una tabla de doble vía a partir de una matriz de sitios o parcelas y especies. Dicho método fue la herramienta para clasificar la vegetación y así definir los tipos florísticos o comunidades vegetales en el área.

\section{Tipos de uso de la tierra}

Se identificaron los diferentes tipos de uso (agricultura / ganadería) y los tipos de cultivo establecidos, relacionados con cada parcela de muestreo. Características como tipo de tenencia de la tierra, tamaño de la propiedad y tipos de cultivo fueron tenidas en cuenta para establecer relaciones entre los remanentes de vegetación y las áreas agrícolas (Seabrook et al., 2007; Thiago F.L.V.B. Rangel et al. 1997). 
Cambios de cobertura a través de un análisis histórico de fotografías aéreas

Se seleccionaron fotografías aéreas de los años 1961 (escala 1: 50 000) y 1988 (escala 1: 30 000) y una imagen satélite ArcGlobe del año 2011 (escala 1:50 000), la interpretación se realizó a una escala de visualización 1:30 000. Se evaluaron los patrones de distribución de los diferentes tipos de cobertura y la relación de la vegetación con el medio; especialmente tendencias en el uso de la tierra. Asimismo, los pobladores de la región suministraron información adicional sobre la historia de uso de la tierra en el área.

Las unidades de vegetación fueron delineadas teniendo en cuenta los criterios de cobertura vegetal natural y cobertura vegetal cultural, las fotocaracterísticas de tono y textura y también el patrón de las áreas de cultivo. Cada atributo de la fotointerpretación fue digitalizado usando el programa ArcGIS con el fin de obtener el mapa de cobertura vegetal y uso de la tierra de los años analizados, asimismo se determinaron las áreas de cobertura y distribución de cada clase de cobertura para cada año.

\section{RESULTADOS}

\section{Caracterización de los patrones de la vegetación y los tipos de uso de la tierra}

\section{Tipos estructurales de vegetación}

Los estratos identificados en la vegetación fueron los siguientes

Estrato arbóreo: la dominancia está dada por árboles con alturas superiores a los $5 \mathrm{~m}$.

Estrato arbustivo: la dominancia se encuentra dada por vegetación de hábito arbustivo o arbóreo, mayor de $1.5 \mathrm{~m}$ y menor de $5 \mathrm{~m}$.

Estrato herbáceo: la dominancia está dada por vegetación menor de $1.5 \mathrm{~m}$.

El porcentaje de cobertura estimado para cada estrato en la parcela, así como también la altura, definieron los tipos estructurales de la vegetación en el Valle del Patía, representados en la Tabla 1. Atendiendo al modelo de Wyngaarden (1985) para las sabanas africanas, se hace énfasis en la distribución y estratificación de la vegetación en tipos herbáceos, arbustivos y arbóreos sin tener en cuenta su composición florística. Con base en estas clasificaciones se definieron para el área seis

Tabla 1. Tipos estructurales de la vegetación del Valle del Patía con base en análisis de conglomerados a través de TWINSPAN. Códigos de cobertura (-) Ausente, $1=1-10 \%, 2=11-20 \%, 3=21-30 \%, 4=31-40 \%, 5=41-50 \%, 6=51$ $60 \%, 7=61-70 \%, 8=71-80 \%, 9=80-100 \%$.

\begin{tabular}{|c|c|c|c|c|c|c|}
\hline & I & II & III & IV & $\mathbf{V}$ & VI \\
\hline & 1111 & 122122355556 & 3333333444444411 & $35666 \quad 166$ & $2566 \quad 35$ & 2222244554 \\
\hline & 5793489 & 158069745670 & 1692460123489012345657 & 684563212 & 7237853 & 0123479018 \\
\hline 1 Altura arbórea & 9788989 & 677777777777 & 7887576677767777777888 & $78666 \ldots$ & $\cdots \cdots$ & $\ldots \ldots$ \\
\hline 2 Cobertura arbórea & 8897687 & 344744464442 & 8997776655751777688865 & $45546 \ldots$ & $\ldots \ldots$ & $\ldots \ldots$ \\
\hline 8 Cobertura hojarasca & 9962313 & $555111111-11$ & $23-3422323212444334333$ & $21 \ldots 5 \ldots$ & $\ldots \ldots$ & $\ldots \ldots$ \\
\hline 3 Altura arbustiva & 4567757 & $4-4454454445$ & $44-5444444444554445456$ & 454445544 & $44 \ldots$. & $\ldots \ldots$ \\
\hline 4 Cobertura arbustiva & 5524214 & $2-2233522231$ & $32-4455566655675565587$ & 797889797 & $35 \ldots$ & \\
\hline 7 Cobertura suelo desnudo & 2111244 & 221522332213 & 1232121222322111321212 & 333343243 & 1142211 & $\ldots$ \\
\hline 5 Altura herbácea & 1233333 & 221212211122 & 1211131211212111112233 & 111222211 & 1123122 & 2222222221 \\
\hline \multirow[t]{7}{*}{6 Cobertura herbácea } & 2216716 & 587585678879 & 5567716535465765676787 & 675457365 & 8947998 & 9999999999 \\
\hline & 0000000 & 000000000000 & 0000000000000000000000 & 000000000 & 1111111 & 1111111111 \\
\hline & 0000000 & 000000000000 & 0000000000000000000000 & 111111111 & 0011111 & 1111111111 \\
\hline & 00000000 & 111111111111 & 1111111111111111111111 & 000001111 & 00111 & 1111111111 \\
\hline & 0001111 & 00000000000000 & 1111111111111111111111 & 00111 & 011 & 1111111111 \\
\hline & & 000111111111 & 0001111111111111111111 & & 00 & 1111111111 \\
\hline & & 011111111 & 0000000000000000011 & & & 000000000001 \\
\hline
\end{tabular}


tipos de vegetación (Figura 2). Los tipos estructurales fueron los siguientes:

I. Vegetación de bosque con cobertura densa y árboles altos: se caracteriza por la presencia de un estrato arbóreo representado aproximadamente por un $80 \%$ de cobertura, con alturas de los árboles entre los $10 \mathrm{~m}$ y los $12 \mathrm{~m}$. El estrato arbustivo representa el $25 \%$ con alturas entre $3 \mathrm{~m}$ y 5 m. Cobertura de hojarasca del $40 \%$, cobertura de suelo desnudo del $12 \%$ aproximadamente y muy poca cobertura herbácea (15\%). Este tipo de vegetación está representada como cobertura de bosque denso.

II. Vegetación de bosque con cobertura semidensa y árboles altos: caracteriza este tipo una cobertura arbórea del $65 \%$ con alturas entre 7 m y 10 m. El estrato arbustivo es del $50 \%$, poca cobertura de suelo desnudo y cobertura de herbáceas de un 50\%, la hojarasca cubre el 30\%. Vegetación representada como cobertura de los bosques riparios.

III. Vegetación de bosque con cobertura abierta y árboles altos: la presencia del estrato arbóreo tiene una cobertura del $40 \%$ con altura de los árboles entre $7 \mathrm{~m}$ y $10 \mathrm{~m}$. El estrato arbustivo es del $20 \%$ y la cobertura de herbáceas es del $60 \%$, comparado con el tipo I las herbáceas presentan un mayor desarrollo así como también una disminución en el porcentaje de hojarasca (30\%). Vegetación representada como cobertura bosque abierto.

IV. Vegetación de cobertura arbustiva: cobertura representada por un gran porcentaje de estrato

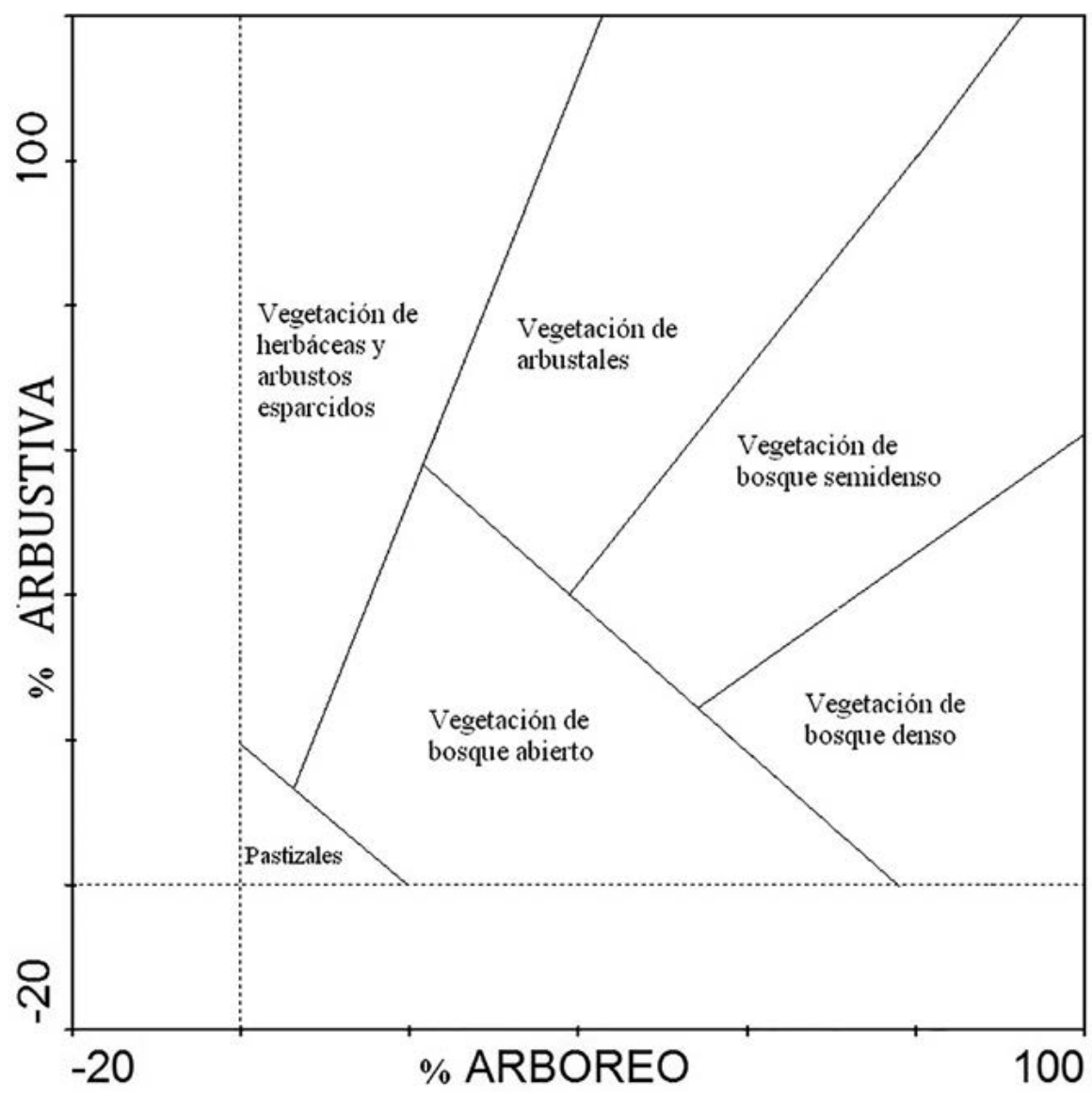

Figura 2. Clasificación de la estructura de la vegetación para el valle del Patía basado en Wyngaarden (1985). 
arbustivo (70\%), donde sobresalen algunos árboles de $6 \mathrm{~m}$ a $7 \mathrm{~m}$, muy poca cobertura de hojarasca y de suelo desnudo. La cobertura de herbáceas es del 50\%. Vegetación representada como cobertura de arbustales.

V. Vegetación de herbáceas y arbustos esparcidos: caracteriza este tipo una cobertura de vegetación herbácea del 70\% con alturas de $1 \mathrm{~m}$. Sobresalen arbustos entre 3 y $5 \mathrm{~m}$. Ausencia de hojarasca y de cobertura arbórea. Vegetación representada como pastizal arbolado.

VI. Vegetación de herbáceas: la cobertura está representada exclusivamente por vegetación herbácea $(90 \%)$, con alturas entre $1 \mathrm{~m}$ y $1.5 \mathrm{~m}$. Vegetación representada en la cobertura de pastizal.

\section{Tipos florísticos de vegetación}

La descripción de los tipos florísticos de vegetación que se realiza a continuación es el resultado del total de especies vegetales registradas y analizadas a través del programa TWINSPAN (Anexo 1 y 2). El gradiente florístico arrojado por el programa describe tipos estructurales que van desde bosques con cobertura densa, bosques abiertos y arbustales hasta herbazales. Los resultados en la primera división (Figura 3) identifican dos grandes tipos de vegetación, una comunidad caracterizada por un componente arbóreo y arbustivo de Guazuma ulmifolia, Eugenia sp. y Zanthoxylum fagara y una comunidad caracterizada por un componente herbáceo de Acacia farnesiana y Desmodium incanum que se dividen en la tercera, cuarta y quinta división en los tipos florísticos que se relacionan a continuación (Figura 4):

\section{Handroanthus chrysanthus-Pithecelobium} lanceolatum $(n=4)$

Es el primer tipo florístico en el gradiente dado por el programa TWINSPAN, representado por cuatro parcelas de muestreo tomadas como referencia en el municipio de Mercaderes, área ubicada en el sur del área de estudio caracterizado por un paisaje de colinas y cuyas coordenadas geográficas corresponden a la zona de menor latitud.

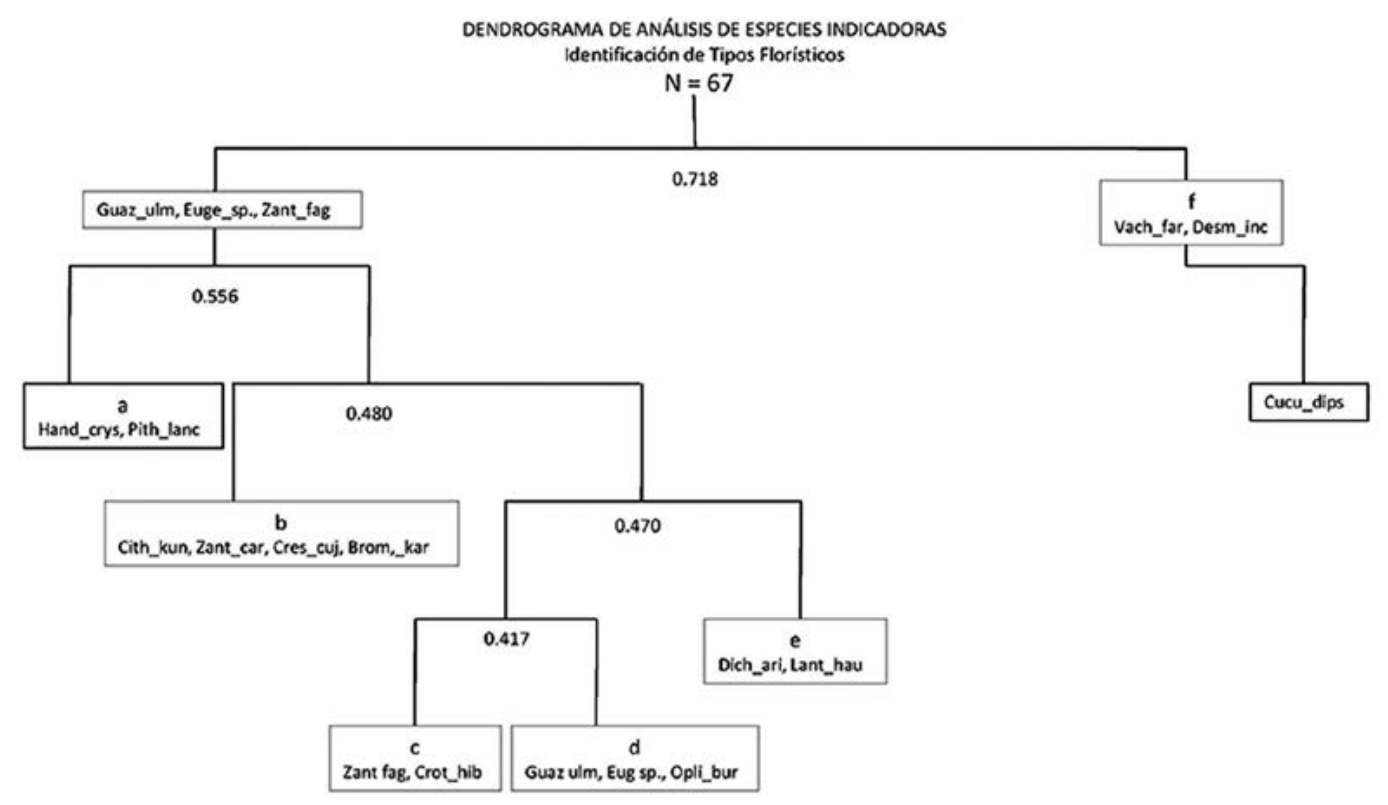

Figura 3. Clasificación de la vegetación y relación entre los seis tipos florísticos del valle del Patía (usando TWINSPAN). 


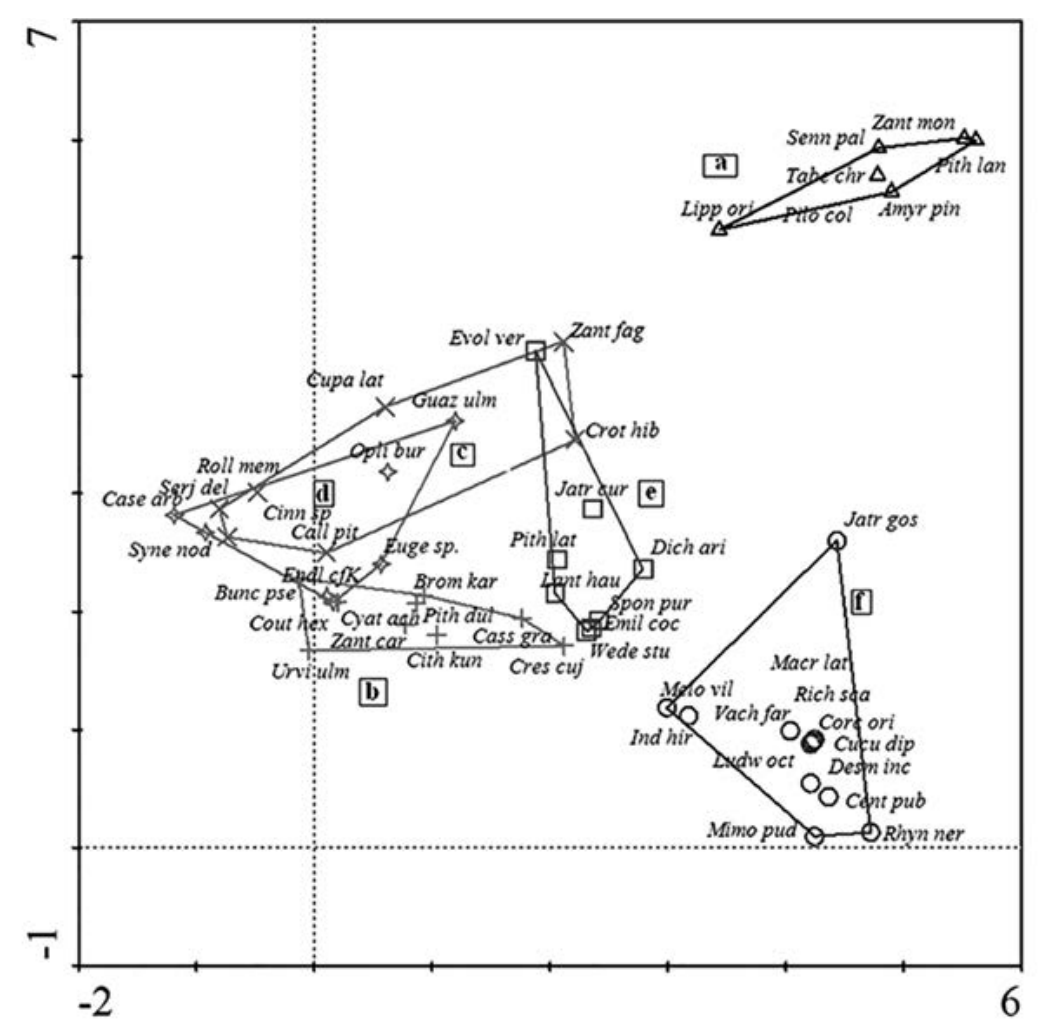

Figura 4. Distribución de los tipos florísticos del Valle del Patía según la ordenación realizada a través de un DCA.

Este tipo florístico corresponde estructuralmente a una vegetación de tipo arbustivo, no ripario, que se caracteriza por una vegetación de áreas muy secas.

\section{Citharexylum kunthianum-Zanthoxylum caribaeum-Crescentia cujete-Bromelia karatas $(n=10)$}

Tipo florístico representado por diez levantamientos, la estructura de la vegetación varía desde los bosques densos y semidensos a los bosques abiertos; corresponden a una vegetación no riparia, que se ubica en la parte central del área de estudio determinado por un parche de bosque de 18 ha que inició su regeneración hace 50 años, según lo observado en las fotografías aéreas de 1961. Este tipo florístico se distingue por la presencia de especies características y dominantes tales como Citharexylum kunthianum y Zanthoxylum caribaeum que le dan el nombre al grupo. La composición florística de este grupo comparte especies como Pithecellobium dulce y Crescentia cujete con otros tipos florísticos.

Zanthoxylum fagara-Croton hibiscifolios $(n=12)$

Este tipo es característico en los drenajes y hondonadas de montañas y colinas así como en bosques riparios, identificándose también como una vegetación de transición hacia pastizales. Zanthoxylum fagara generalmente se ubica en áreas de borde, Croton hibiscifolios se encuentra en el estrato herbáceo y en el estrato arbustivo.

Guazuma ulmifolia-Eugenia sp.-Oplismenus burmanii $(n=14)$

Tipo florístico encontrado preferencialmente en las márgenes de las quebradas, es componente de los bosques riparios, estructuralmente representado por áreas de bosques algunas veces densos, otros semidensos y abiertos, sin embargo comparte algunas características de vegetación de transición a pastizales con especies como Zanthoxylum 
fagara. El estrato herbáceo es dominado por Oplismenus burmanii.

\section{Dichanthium aristatum-Lantana haughtii $(n=7)$}

Tipo florístico de pastizales-arbustales o de árboles esparcidos, que se encuentran en los potreros como sombrío. Este tipo es el componente de las cercas.

Acacia farnesiana - Desmodium incanum $(n=20)$ Este tipo es el característico de los grandes pastizales, se identifica un subtipo de vegetación herbácea caracterizado por Cucumis dipsaceus.

\section{Tipos de uso de la tierra}

El uso de la tierra, determinado por las actividades e intervenciones que la gente realiza, en búsqueda principalmente de un tipo de producción y satisfacción, está caracterizado en la región del Patía por prácticas comúnmente asociadas con procesos de deforestación. Estas áreas, con una larga historia de uso, han sido modificadas por las actividades humanas durante los últimos 300 años.

Se definieron cuatro clases de tipos de uso de la tierra, realizando ajustes a la propuesta de laclasificación de la FAO (2005) y Huizing (1994). Las clases identificadas fueron:

a. Usos basados en producción primaria, representados por la agricultura y dominado por cultivos de pancoger

b. Usos basados en producción secundaria, representada por la ganadería en donde sobresale un pastoreo extensivo. c. Usos basados en infraestructura, representada por carreteras y asentamientos

d. Uso natural, basado en los servicios de los fragmentos de bosque (extracción de leña y disposición de agua en época de sequía para el ganado)

\section{Cambios de cobertura a través de un análisis histórico de fotografías aéreas}

\section{Los cambios de cobertura y uso de la tierra (1961-1988-2011)}

En 1961 el área del valle del Patía presentaba más remanentes de áreas boscosas que las que presentaba en el año 1988 y las presentes en el año 2011; estos remanentes corresponden a $8.7 \%$ de bosques densos y $6.8 \%$ de bosques abiertos tomando como referencia el área de estudio que son 3900 ha (Figura 5). Es importante anotar que infraestructuras como vías que comunican a la carretera panamericana y atraviesan campos de cultivo han permanecido hasta el momento

Para el año 1988, las fotografías aéreas indican una disminución de las áreas de bosque y un aumento de las áreas de pastizales que representan el $22.5 \%$ del área (Figura 6).

\section{Cobertura y uso 2011}

Se identificó para el área siete clases de cobertura con su respectivo uso (Tabla 2, Figura 6) De estas clases algunas han permanecido desde 1961 y otras han tenido variaciones o cambios que se

Tabla 2. Clases de cobertura y uso identificadas en el Valle del Patía para el año 2011.

\begin{tabular}{lll}
\hline \multicolumn{1}{c}{ Cobertura } & \multicolumn{1}{c}{ Uso } & \multicolumn{1}{c}{ CaracterísticaS } \\
\hline Bosque denso & Pastoreo, extracción & Cobertura de estrato arbóreo $>80 \%$ y copas de los árboles entrelazadas. \\
Bosque abierto & Pastoreo, extracción & Cobertura de estrato arbóreo $>50 \%$ y $<80 \%$ \\
Bosque ripario & Pastoreo, extracción & Bosque denso o abierto a orillas de quebradas \\
Arbustal & Pastoreo & Cobertura de estrato arbustivo $>80 \%$ \\
Cultivo & Pancoger & Dominado por especies cultivadas \\
Pastizal & Pastoreo & Dominado por hierbas y por muy poca presencia de especies arbóreas y arbustivas \\
Pastizal arbolado & Pastoreo & Dominado por hierbas y presencia de especies arbóreas y arbustivas \\
Suelo desnudo & Pastoreo & Sin presencia de cobertura vegetal o vegetación herbácea esporádica o matorrales aislados \\
\hline
\end{tabular}




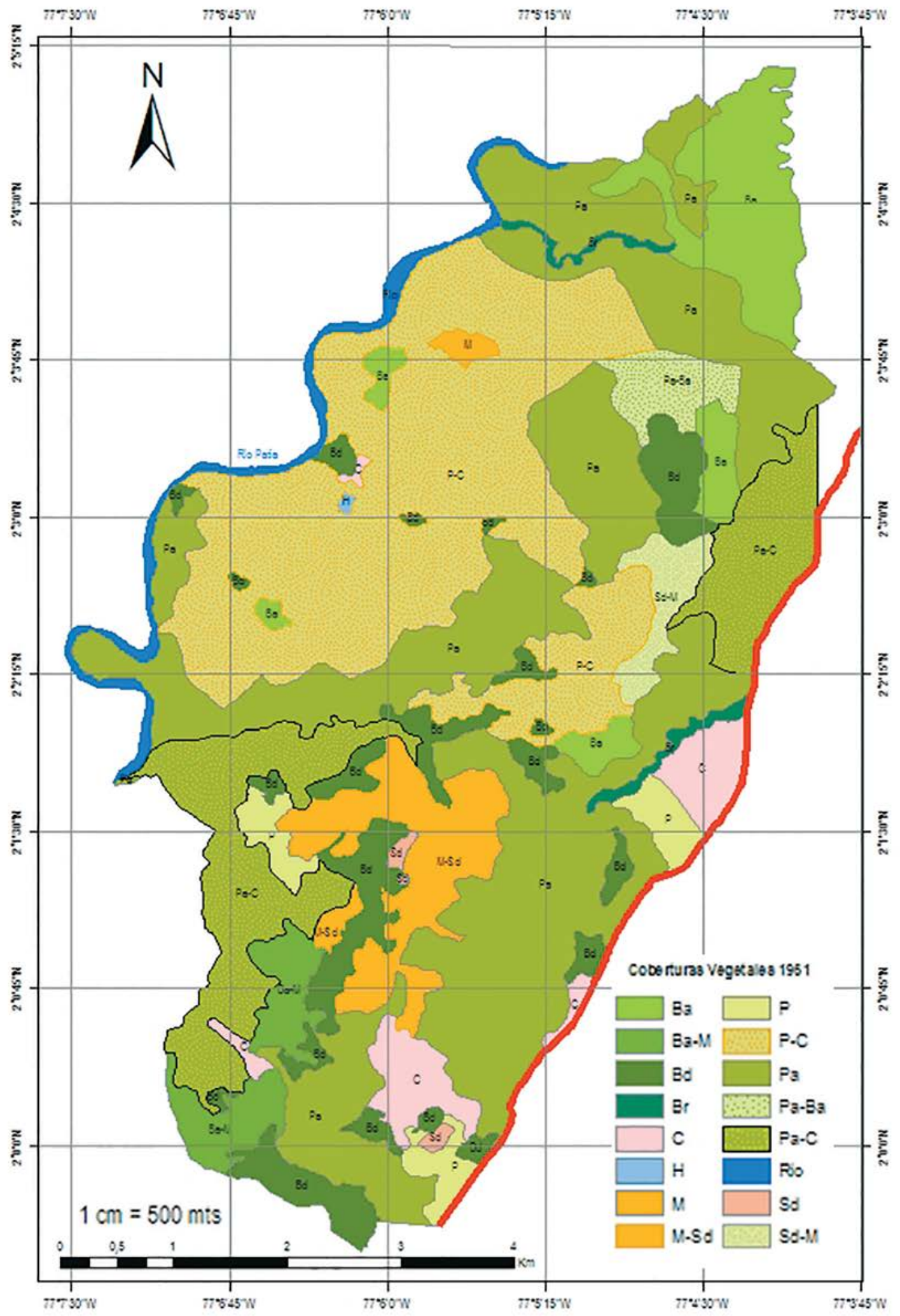

Figura 5. Mapa de cobertura vegetal del Valle del Patía, año 1961. 


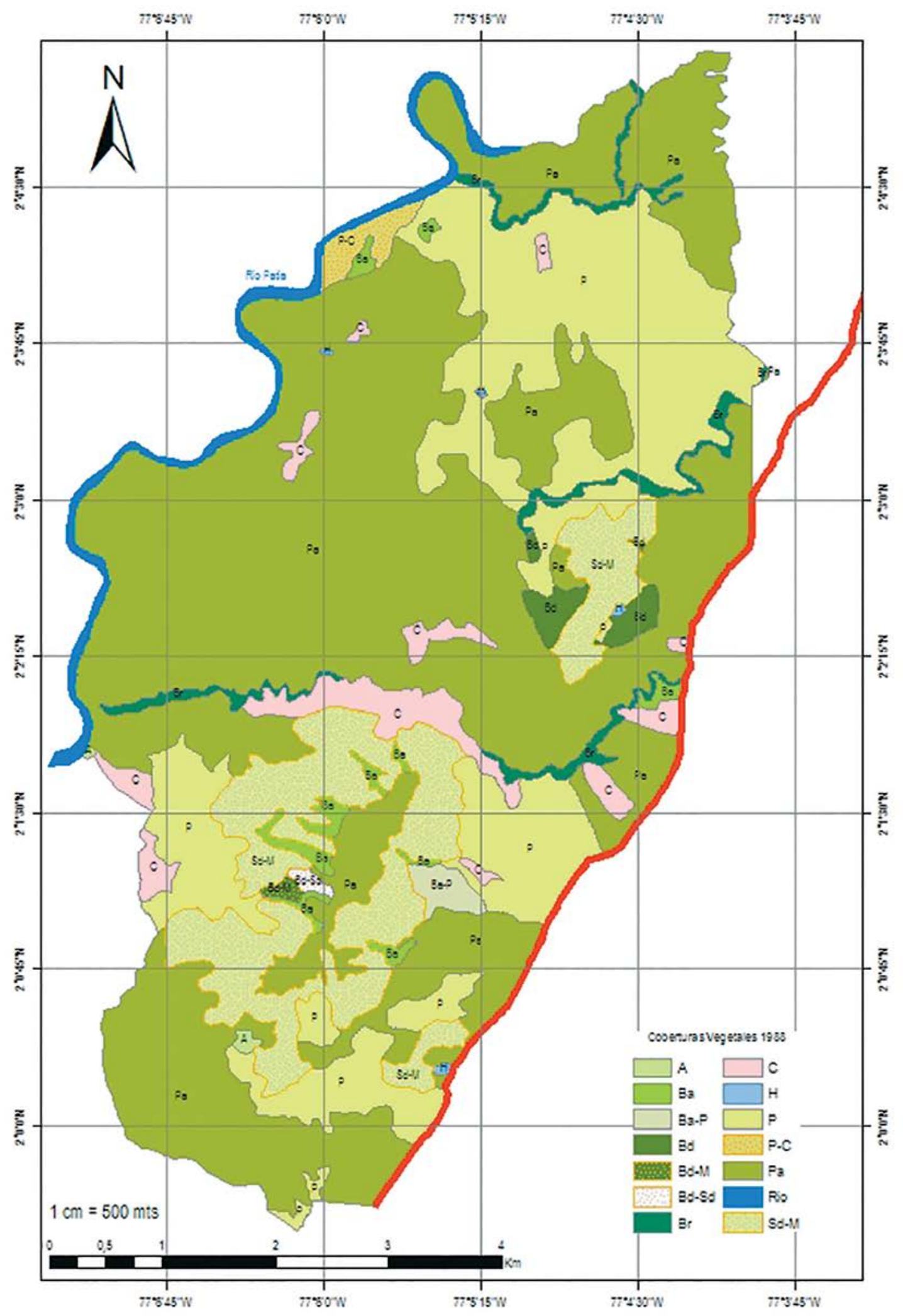

Figura 6. Mapa de cobertura vegetal del Valle del Patía, año 1988. 


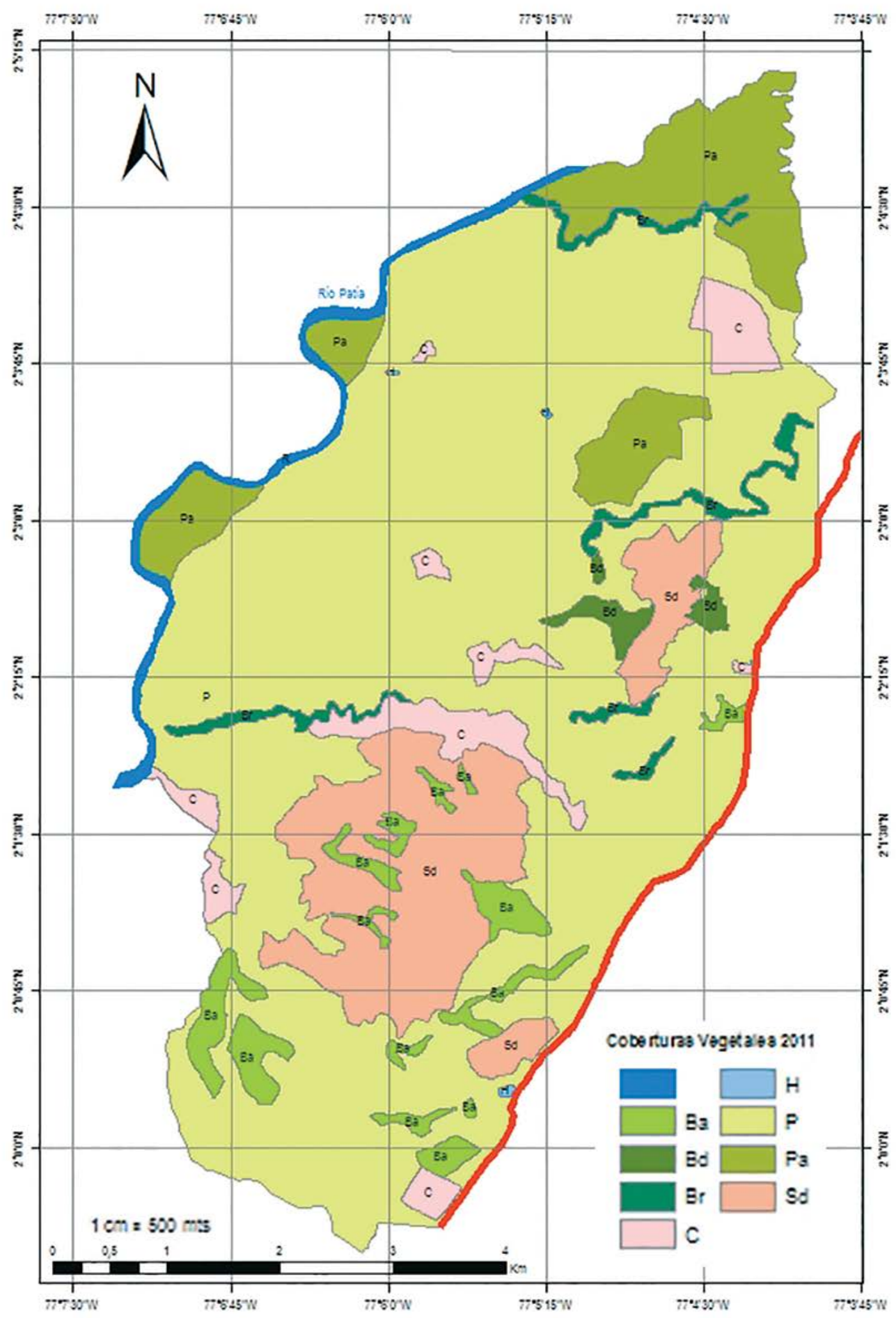

Figura 7. Mapa de cobertura vegetal del Valle del Patía, año 2011. 
evidencian en la extensión de las áreas como se observa en las figuras 5 y 7.

En la región más al sur en El Cardo, municipio de Mercaderes, la cobertura vegetal muestra grandes variaciones desde los años 1961 hasta 1988 y desde este año hasta al 2011 la cobertura no ha presentado grandes modificaciones. Extensas áreas de bosque abierto presentes en 1961 se modificaron hacia complejos de arbustales y suelo desnudo (Figura 8).

La cobertura vegetal ha tenido grandes cambios entre 1961, 1988 y 2011 (Figura 9). Los bosques, incluyendo los bosques densos, bosques abiertos y bosques riparios disminuyeron en área, de 15.5 \% en 1961 a 7\% en 2011, mostrando un leve aumento desde 1988. Del análisis de las fotografías aéreas se destaca que áreas de bosque actuales fueron derivadas de pastizales arbolados que fueron abandonados, es el caso del sitio La Pachuca que después de 30 años aproximadamente presenta un bosque en estado avanzado de sucesión, en el cual se realizaron veinte levantamientos de vegetación para su caracterización.

Durante los años 1961 y 1988 las áreas para la ganadería representada por los pastizales arbolados dominaban el paisaje ( $44.4 \%$ y $54.3 \%$ ), mientras que las áreas de suelo desnudo ocupaban bajo porcentaje (0.24\% y $1.96 \%$ ). En 2011 , el paisaje estaba dominado por pastizales (68\%) y aumento de las áreas de suelo desnudo (12\%). Las áreas de suelo desnudo se presentan principalmente en montañas y colinas aisladas suavemente estratificadas que corresponden al cerro de Manzanillo, cerro de La Pachuca y cerro de la Tortuga o de La India. Los complejos de Bosque abierto-Pastizal o los pastizales arbolados desaparecieron para ocupar grandes áreas de pastizal.

La distribución geográfica de las clases de cobertura muestran un mismo patrón de ocurrencia durante los años analizados, como es el caso de los suelos desnudos que ocupan las áreas de colinas y montañas, los bosques ubicados en las hondonadas y el establecimiento de pastizales en el valle aluvial y en colinas muy bajas.

\section{DISCUSIÓN}

\section{Tipos estructurales de vegetación}

La vegetación en el valle del Patía está representada por pastizales (grandes extensiones para la ganadería), vegetación herbácea de áreas en recuperación después de un uso ganadero o agrícola, vegetación arbustiva y arbórea de bosques riparios y de pequeños parches de bosque.

La estratificación de la vegetación en bosques secos tropicales presenta patrones característicos; Murphy \& Lugo (1986) afirman que generalmente los bosques secos son más reducidos en su estructura y más simples en su composición, con una altura del dosel que va desde los $2 \mathrm{~m}$ en áreas de bosque perturbados con mucha intervención hasta los $40 \mathrm{~m}$ en bosques maduros protegidos, según estudios realizados en Centroamérica y el Caribe; Díaz (2006) afirma que los bosques primarios presentan cinco capas o estratos (inferior, medio, superior y las zonas no arbóreas más cercanas al suelo) y resalta que debido al alto grado de intervención humana de estos ecosistemas solo es posible identificar tres o cuatro estratos.

Los tres estratos identificados en el área, arbóreo, arbustivo y herbáceo dan cuenta de los patrones característicos de los bosques secos tropicales (reducidos en su estructura), teniendo en cuenta que son bosques perturbados.

El porcentaje de cobertura y las alturas de cada estrato fueron fundamentales para la identificación de los tipos estructurales determinados a través del análisis de conglomerados realizado, también contribuyeron los datos del porcentaje de hojarasca y de suelo desnudo. El porcentaje de cobertura definió totalmente los tipos de vegetación usados en el modelo dado por Wyngaarden (1985). Ambos análisis definieron desde el punto de vista de la cobertura los mismos tipos estructurales de vegetación.

De los seis tipos estructurales para la vegetación estudiada, de los cuales tres tipos: vegetación de bosque con cobertura densa y árboles altos, 

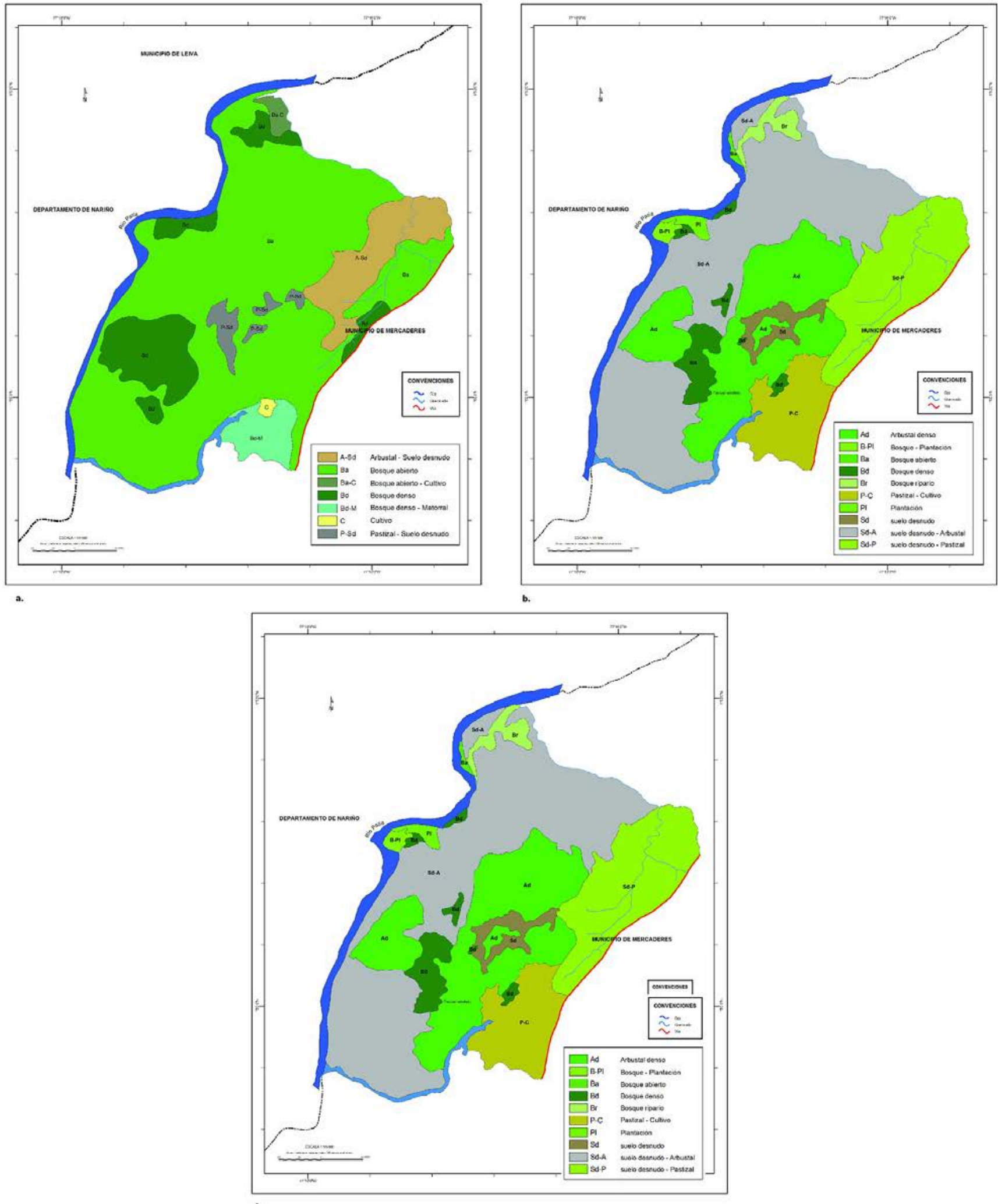

Figura 8. Cobertura vegetal para el área de El Cocal, Municipio de Mercaderes para los años (a) 1961 (b) 1988 y (c) 2011. 

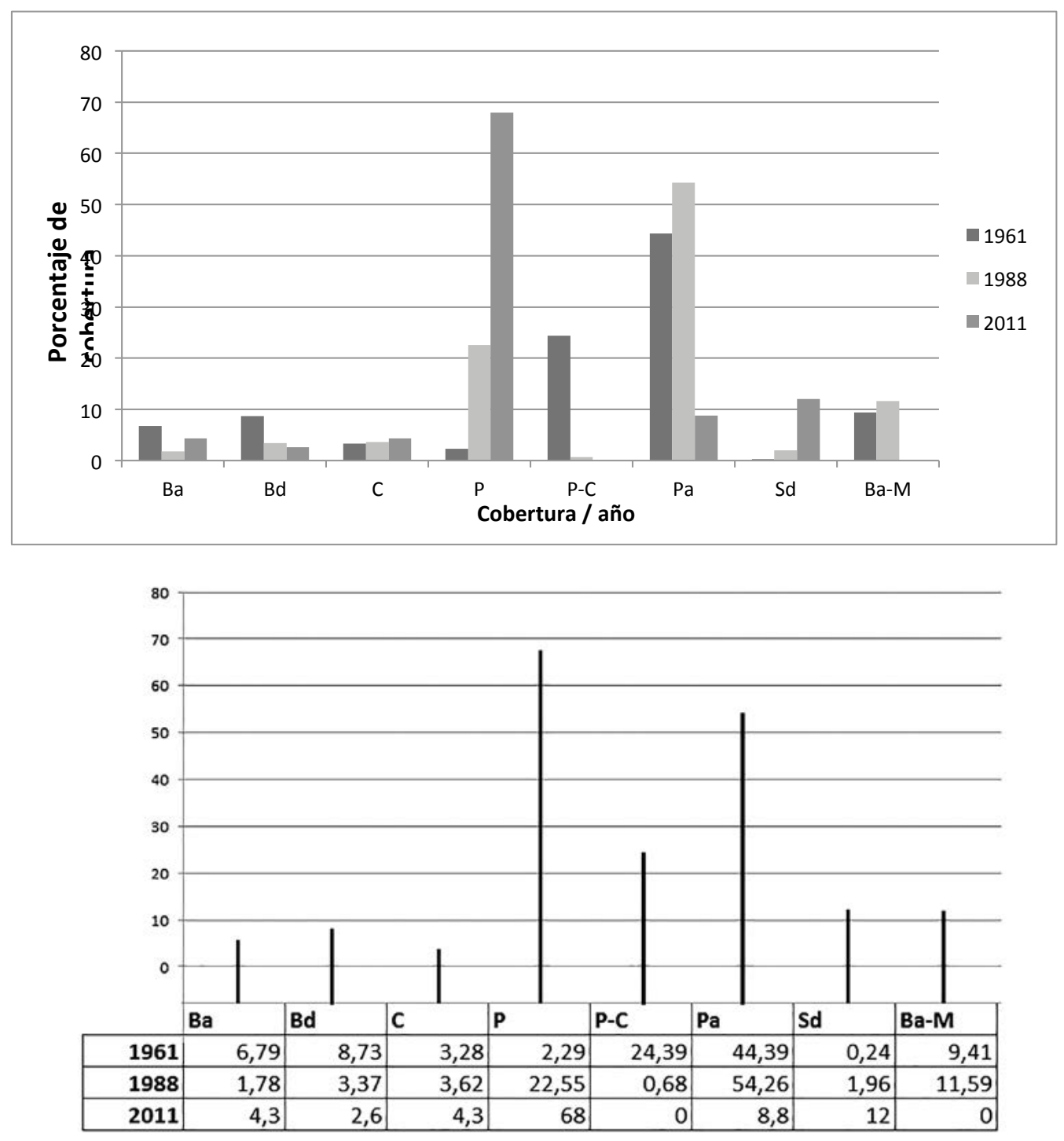

Figura 9. Distribución de las clases de cobertura en el área de estudio para los años 1961, 1988 y 2011 y porcentaje de cobertura para cada clase.

vegetación de bosque con cobertura abierta y árboles altos, vegetación de bosque con cobertura semidensa y árboles altos y Vegetación de cobertura arbustiva, se destacan por caracterizar a la vegetación del bosque seco tropical del Patía.

\section{Tipos florísticos de vegetación}

Este estudio es la primera aproximación de esta clasificación en los bosques secos del Patía en el departamento del Cauca. Ariza (1999) realizó una caracterización de la vegetación en el enclave árido del río Patía en el departamento de Nariño y definió las comunidades vegetales del área basado en este método.

Numerosos estudios se han realizado aplicando estos métodos de clasificación, sobresalen los realizados en ecosistemas de páramos y bosques andinos (Rangel et al, 1997; Verweij, 1995); Albesiano et al., (2003) aplicó este método para 
determinar asociaciones en los matorrales del cañón del río Chicamocha; Fandiño (2010) hace un análisis de comunidades presentes en el área de La Tatacoa. Los grupos de comunidades identificadas en las divisiones obtenidas en el programa y diferenciadas por sus características estructurales y florísticas corresponden con el tipo estructural de vegetación de bosque y representan los pocos fragmentos de este ecosistema en la región del Patía; de los seis tipos florísticos definidos, tres tipos (B, C, y D) son estructuralmente comunidades boscosas. El método fue apropiado debido a que condensó la información sobre la presencia y variación de las especies vegetales del Patía.

Asimismo, las comunidades identificadas son un reflejo de lo que se observa en el área, el bosque de La Pachuca, fragmento que se encuentra en estado sucesional desde el año 1961 y caracterizado por la comunidad de Citharexylum kunthianum contrasta con los bosque de Versalles en su mayoría como componentes riparios determinados por la comunidad de Eugenia sp. especie dominante y abundante (72\%) en áreas intervenidas y de uso para ganadería. La comunidad de Handroanthus chrysanthus es una muestra importante de la zona de transición hacia la vegetación de matorrales xerofíticos del sur del país.

\section{Tipos de uso de la tierra y cambios de cobertura}

Las perturbaciones naturales son importantes fuerzas de cambios ecológicos y el entendimiento de esta variabilidad de los ecosistemas incrementa el conocimiento para el manejo de las áreas.

Prácticas de uso de la tierra también ejercen profundos impactos en los sistemas naturales, actividades como cultivos, pastoreo y extracción determinan la estructura, composición y función y podrían ser incluidos en futuros planes de manejo.

La historia del uso de la tierra puede ser particularmente importante en regiones como el Patía que han sido intervenidas por cientos de años. Identificar el papel de las actividades humanas del pasado frecuentemente es difícil debido a lo poco documentado y puede ser correlacionado con el ambiente físico identificando el uso de la tierra como determinante en los patrones de la vegetación actuales.

En la larga historia de uso y de perturbaciones que lleva esta área por cientos de años, los resultados han demostrado que desde 1961 hasta el año 2011, el paisaje ha tenido muy pocos cambios, se evidencia una reducción de los fragmentos de bosque determinado por la ampliación de áreas para uso agrícola y ganadero; los factores sociales y económicos son una fuerza de cambio de las comunidades vegetales en áreas rurales, indicando que los cambios en la vegetación son afectados directamente por la sostenibilidad en el uso de la tierra. Los bosques densos y abiertos y los pastizales arbolados redujeron el área, y más que el área desaparecieron muchos fragmentos y por lo tanto la representatividad de estos ecosistemas en el Patía. Este estudio no enfatiza en un análisis espacial de fragmentos de bosque, pero sí pretende mostrar una visión general del estado actual de la vegetación en los fragmentos aun presente $y$, a partir de estos resultados las instituciones y organizaciones propongan estrategias para la conservación de los relictos actuales y la defensa del patrimonio natural. Los pastizales han incrementado su cobertura lo cual significa un uso más enfocado hacia el pastoreo, áreas transformadas están relacionadas con altos porcentajes de pastizales y con un extensivo uso de la tierra en las áreas bajas de los andes (Etter \& Wyngaarden, 2000); como sucede en este valle interandino. Es de resaltar que las áreas de cultivo mostraron un incremento muy leve (de 3.28 en 1961 a 4.3 en 2011), representado en agricultura de subsistencia.

\section{CONCLUSIONES}

Para el Valle del Patía, departamento del Cauca, suroccidente de Colombia, se identificaron seis tipos estructurales de vegetación representados por 
árboles altos hasta de $12 \mathrm{~m}$, arbustos y herbáceas hasta de $1.5 \mathrm{~m}$; ocho clases de cobertura dada por una vegetación densa y semidensa; coberturas arbustivas y herbáceas. La cobertura de hojarasca no fue relevante en la definición de los tipos estructurales y el suelo desnudo definió un tipo de cobertura.

En la definición de los tipos florísticos se destacan dos grandes comunidades, una caracterizada por un componente arbóreo y arbustivo y otra comunidad caracterizada por un componente herbáceo. Especies como Guazuma ulmifolia y Eugenia sp. dan cuenta del estado sucesional de estos bosques. El tipo florístico Handroanthus chrysanthus-Pithecelobium lanceolatum es una comunidad representativa de la transición hacia zonas muy secas del sur del departamento del Cauca y del país.

Las coberturas boscosas disminuyeron en 50 años y las áreas de pastizales y suelo desnudo aumentaron, esto indica que el uso de tierras para uso ganadero aumentó y el incremento para áreas de cultivo fue muy poco. La realización de una estrategia de conservación de los bosques secos del Patía con participación de organizaciones estatales y privadas y de la comunidad que habita la región es de gran conveniencia para poder generar iniciativas de restauración y protección de los remanentes de bosque seco del Patía.

\section{AGRADECIMIENTOS}

Especial agradecimiento a Willem Wyngaarden del Grupo Arco, Alba Marina Torres de la Universidad del Valle, a Bernardo Ramírez, director del Herbario de la Universidad del Cauca por su colaboración en el proceso de identificación del material colectado, a Dora Troyano en el montaje de las muestras y a María Alejandra González por su grato apoyo en el Patía.

\section{REFERENCIAS BIBLIOGRÁFICAS}

Albesiano, S., Rangel-Ch, J.O., Cadena A. (2003). La vegetación del río Chicamocha (Santander, Colombia). Caldasia, 25(1), 73-99.

Ariza, C. (1999). Estudio de la diversidad florística del enclave árido del río Patía (Colombia). (Trabajo de grado para obtener el título de Bióloga). Bogotá: Universidad Nacional de Colombia, Facultad de Ciencias, Departamento de Biología-Instituto de Ciencias Naturales. 124 p.

Díaz, J.M. (2006). Bosque Seco Tropical Colombia. Cali: Banco de Occidente.

Etter A., Wyngaarden W. (2000). Patterns of Landscape Transformation in Colombia, with emphasis in the Andean Region. AMBIO: A Journal of the Human Environment, 29(7), 432-439.

Fandiño-Lozano, M. (2010). Parque Natural Regional La Tatacoa. De prioridad de conservación a realidad. Bogotá: Grupo ARCO. 130 p.

Food and Agriculture Organization of the United Nations-FAO-. (2005). Land cover classification system- Classification concepts and user manual. Roma: Food and Agriculture Organization of the United Nations. 208p.

Gentry, A.H. (1988). Changes in plant community Diversity and floristic composition on environmental and geographical gradients. Annals of the Missouri Botanical Garden, 75(1), 1-34.

Hill, M.O. \& Šmilauer, P. (2005). TWINSPAN for Windows version 2.3. Centre for Ecology and Hydrology \& University of South Bohemia, Huntingdon \& Ceske Budejovice. 29p.

Holdridge, L. (1996). Ecología basada en zonas de vida. San José de Costa Rica: Instituto Interamericano de Cooperación para la Agricultura -IICA-. $216 \mathrm{p}$.

Huizing, H. (1994). Land Evaluation. International Institute for Aerospace survey and earth science. The Netherlands. 86p.

Kent, M. \& P. Coker. (1992). Vegetation description and analysis: a practical approach. Great Britain: CRC Press. 363p. 
Ministerio del Medio Ambiente. (2002). Desertificación y sequía. Segundo Informe Nacional. Bogotá: Ministerio del Medio Ambiente. 51 p.

Murphy, P.\& A. E. Lugo. (1986). Ecology of tropical dry forest. Annual Review of Ecology and Systematic, 17, 67-88.

Pennington, R. T., Prado, D. E., \& Pendry, C. A. (2000). Neotropical Seasonally Dry Forests and Quaternary Vegetation Changes. Journal of Biogeography, 27(2), 261-273.

Rangel-Ch, J.O., Lowy, P., Aguilar, M. (1997). Distribución de los tipos de vegetación en las regiones naturales de Colombia. Aproximación inicial. En J.O. Rangel-Ch, Lowy-C, P., Aguilar-P, M. (eds.). Diversidad Biótica II. Tipos de Vegetación en Colombia (pp. 403-436). Bogotá: Universidad Nacional de Colombia-Instituto de Ciencias Naturales, Instituto de hidrología, Meteorología y estudios Ambientales (IDEAM)-Ministerio del Medio Ambiente, Comité de Investigaciones y Desarrollo Científico-CINDEC.U.N, Academia Colombiana de Ciencias Exactas, Físicas y Naturales.

Rangel-Ch, J.O. \& G. Lozano. (1986). Un perfil de vegetación entre La Plata (Huila) y el volcán del Puracé. Caldasia, 14 (68-70), 503-547.
Seabrook, L., McAlpine, C., Fensham, R. (2007). Spatial and temporal analysis of vegetation change in agricultural landscapes: A case study of two brigalow (Acacia harpophylla) landscapes in Queensland, Australia. Agriculture, Ecosystems and Environment, 120, 211-228.

Thiago F.L.V.B. Rangel, Bini, L. M., Diniz_Filho, Plaza, M., Carvalho, P., Bastos, R. (2007). Human development and biodiversity conservation in Brazilian Cerrado. Applied Geography, 27, 14-27.

Van der Hammen, T., D. Mueller-Dombois \& M. A. Little. (1989). Manual of Methods for Mountain Transect Studies-Comparative Studies of Tropical Mountain Ecosytems. Decade of be Tropics Program of IUBS. Paris: International Union of Biological Sciences (IUBS). 66 p.

Verweij, P. (1995). Spatial and temporal modelling of vegetation patterns. The Netherlands: ITC. 233 p.

Wyngaarden, W. van. (1985). Elephants, Trees, Grass and Grazers. Relationships between climate, soiIs, vegetation and large herbivores in a semi-arid savannah ecosystem (Tsavo, Kenya). The Netherlands: ITC, Enschede. 134 p. 


\section{Anexo 1. Tipos florísticos de vegetación - Valle del Patia.}

$\mathbf{A}$
B

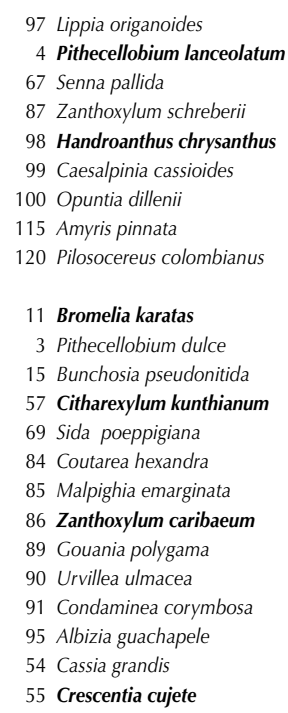

5 Zanthoxylum fagara

7 Annona muricata

9 Croton sp.

13 Calliandra pittieri

16 Musa paradisiaca

18 Triumfetta sp.

19 Cinnamomum sp.

20 Psychotria micrantha

21 Cupania latifolia

23 Eugenia acuminata

26 Phoradendron quadrangulare

106 Cordia lanceolata

111 Oryctanthus alveolatus

114 Serjania deltoidea

117 Prosthechea livida

25 Rollinia membranacea

8 Croton hibiscifolius

24 Dioclea sericea

10 Eugenia sp.

79 Cyathula achyranthoides

88 Endlicheria sp.

1 Guazuma ulmifolia

116 Commelina sp.

6 Oplismenus burmannii

12 Duranta obtusifolia

22 Cupania americana

27 Casearia arborea

28 Sapindus saponaria

44 Mucuna pruriens

45 Hyptis mutabilis

47 Crotalaria nitens

49 Synedrella nodiflora

56 Ficus obtusifolia

82 Capsicum annuum

101 Polygala asperuloides

109 Erythroxylum haughtii

112 Anemia sp.
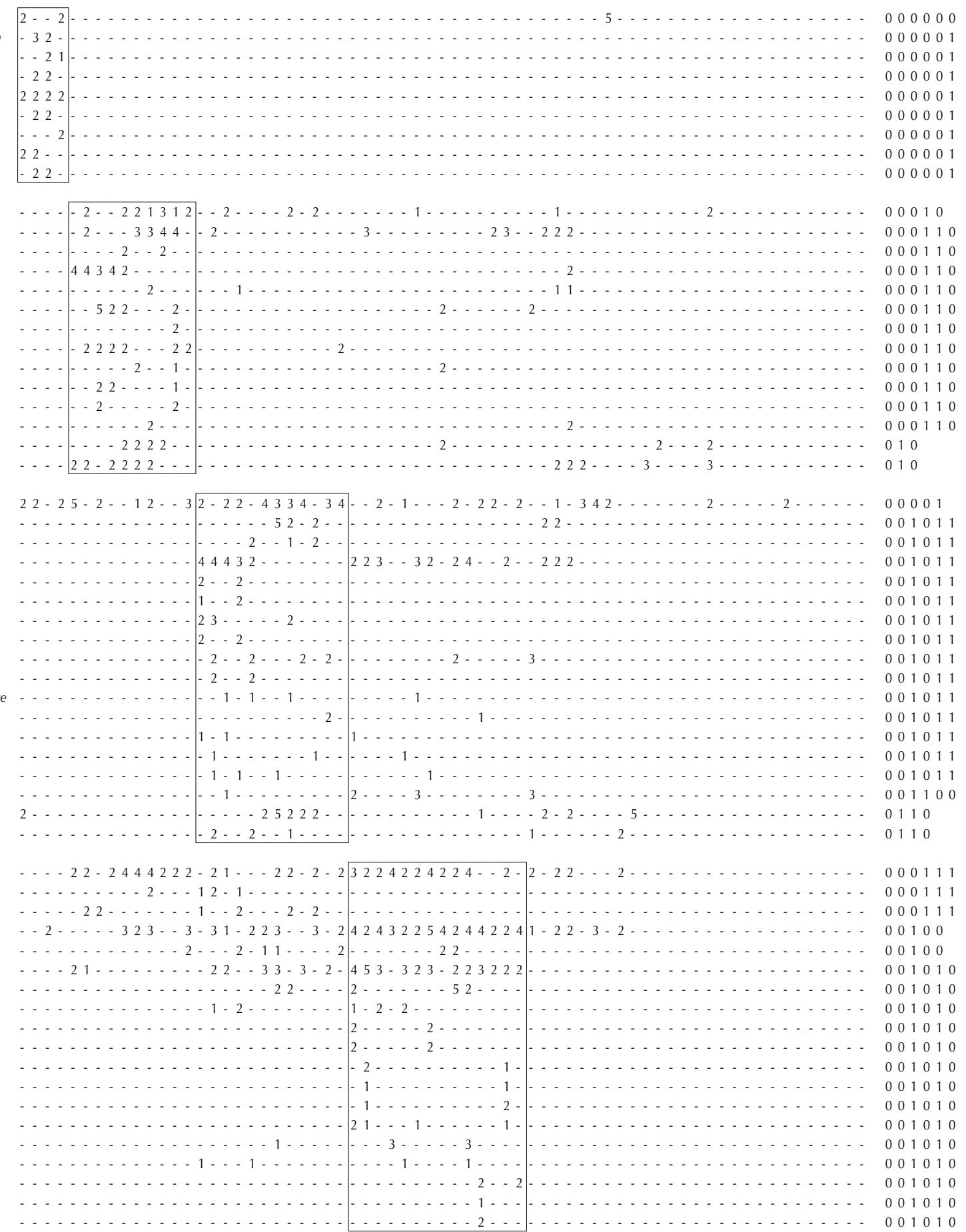

$\begin{array}{lllllll}0 & 0 & 0 & 0 & 1\end{array}$

$\begin{array}{llllll}0 & 0 & 1 & 0 & 1 & 1\end{array}$

0001011

0001011

$\begin{array}{lllllll}0 & 0 & 1 & 0 & 1 & 1\end{array}$

0001011

$\begin{array}{llllll}0 & 0 & 1 & 0 & 1 & 1\end{array}$

$\begin{array}{llllll}0 & 0 & 1 & 0 & 1 & 1\end{array}$

0001011

0001011

0001011

00011011

00011011

0011011

0001011

001100

0110

0110

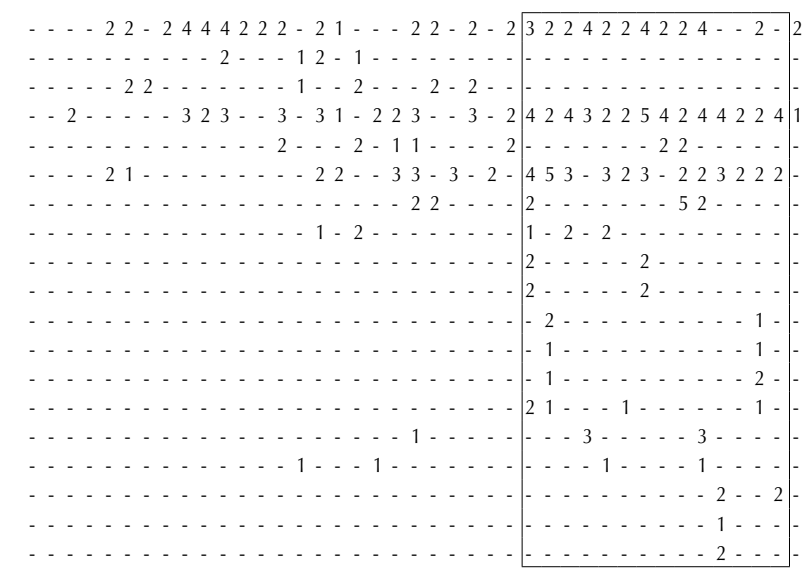

0000111

00001111

0000111

$\begin{array}{lllllllllllllll}0 & 0 & 1 & 0 & 0\end{array}$

00100

001010

001010

00010110

001010

$\begin{array}{llllllllllllll}0 & 0 & 1 & 0 & 1 & 0\end{array}$

00101010

001010

$\begin{array}{llllllllllllllll}0 & 0 & 1 & 0 & 1 & 0\end{array}$

0011010

001010

$\begin{array}{lllllllllllllll}0 & 0 & 1 & 0 & 1 & 0\end{array}$

$\begin{array}{lllllllllll}0 & 0 & 1 & 0 & 1 & 0\end{array}$

001010

001010 
Patrones de la vegetación y tipos de uso de la tierra en el valle del Patía

Vergara V, $\mathrm{H}$.

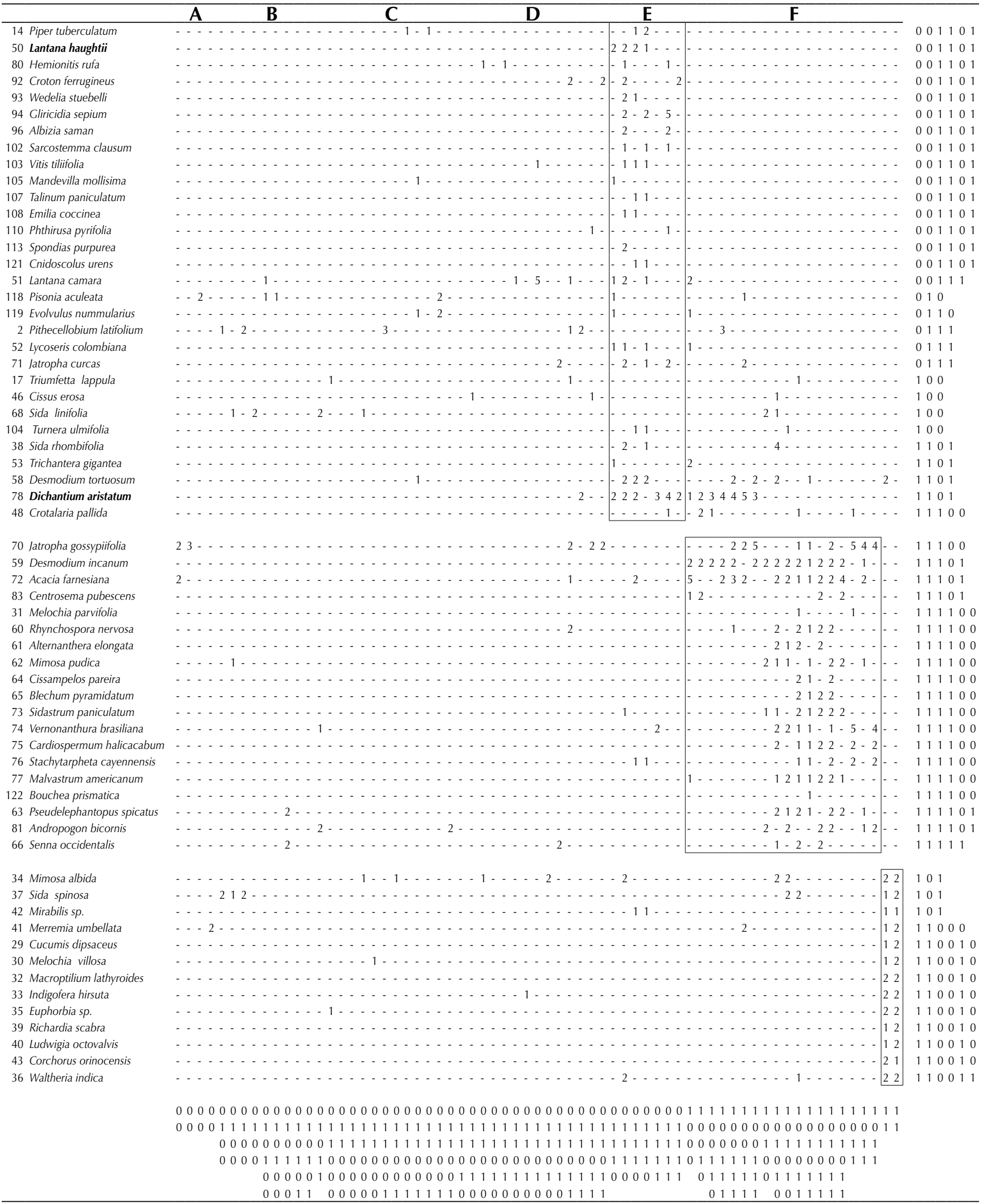




\section{Anexo 2. Composición de especies de los 67 sitios de muestreo. Especies dominantes (presencia/abundancia $>10 \%$ )}

\begin{tabular}{|c|c|}
\hline Grupo fitosociológico & Otras especies características \\
\hline $\begin{array}{l}\text { a. Handroanthus chrysanthus } \\
\text { Pithecelobium lanceolatum }\end{array}$ & Lippia origanoides \\
\hline $\begin{array}{l}\text { b. Citharexylum kunthianum } \\
\text { Zanthoxylum caribaeum } \\
\text { Crescentia cujete } \\
\text { Bromelia karatas }\end{array}$ & $\begin{array}{l}\text { Pithecelobium dulce } \\
\text { Cassia grandis } \\
\text { Citharexylum kunthianum } \\
\text { Coutarea hexandra }\end{array}$ \\
\hline $\begin{array}{l}\text { c. Zanthoxylum fagara } \\
\text { Croton hibiscifolius }\end{array}$ & $\begin{array}{l}\text { Annona muricata } \\
\text { Calliandra pittieri } \\
\text { Cupania latifolia }\end{array}$ \\
\hline $\begin{array}{l}\text { d. Guazuma ulmifolia } \\
\text { Eugenia sp. } \\
\text { Oplismenus burmanii }\end{array}$ & $\begin{array}{l}\text { Durantha obtusifolia } \\
\text { Commelina sp }\end{array}$ \\
\hline $\begin{array}{l}\text { e. Dichanthium aristatum } \\
\text { Lantana haughtii }\end{array}$ & $\begin{array}{l}\text { Pithecelobium latifolium } \\
\text { Lantana camara } \\
\text { Desmodium tortuosum }\end{array}$ \\
\hline $\begin{array}{l}\text { f. Acacia farnesiana } \\
\text { Desmodium incanum }\end{array}$ & $\begin{array}{l}\text { Mimosa albida } \\
\text { Sida spinosa } \\
\text { Mimosa pudica } \\
\text { Rhynchospora nervosa } \\
\text { Pseudelephantopus spicatus } \\
\text { Jatropha gossypiifolia } \\
\text { Sidastrum paniculatum } \\
\text { Vernonanthura brasiliana } \\
\text { Cardiospermum halicacabum } \\
\text { Stachytarpheta cayennensis } \\
\text { Malvastrum americanum } \\
\text { Andropogon bicornis }\end{array}$ \\
\hline
\end{tabular}


